OPEN ACCESS

Citation: E. Topçu (2021) Testing of Drought Exceedance Probability Index (DEPI) for Turkey using PERSIANN data for 2000-2021 period. Italian Journal of Agrometeorology (2): 15-28. doi: 10.36253/ijam-1308

Received: May 06, 2021

Accepted: August 17, 2021

Published: December 27, 2021

Copyright: (c) $2021 \mathrm{E}$. Topçu. This is an open access, peer-reviewed article published by Firenze University Press (http://www.fupress.com/ijam) and distributed under the terms of the Creative Commons Attribution License, which permits unrestricted use, distribution, and reproduction in any medium, provided the original author and source are credited.

Data Availability Statement: All relevant data are within the paper and its Supporting Information files.

Competing Interests: The Author(s) declare(s) no conflict of interest.

ORCID:

ET: 0000-0003-0728-7035

\section{Testing of Drought Exceedance Probability Index (DEPI) for Turkey using PERSIANN data for 2000-2021 period}

\author{
EMrE TOPÇU \\ Kafkas University, Civil Engineering Department, 36100, Kars, Turkey \\ E-mail: emretopcu01@gmail.com
}

\begin{abstract}
Drought is a climatic event that threatens the environment and human life with an ambiguity of location and time. Recently, droughts can be analyzed for different periods with the help of different mathematical methods and developing technology. This study aims to perform a drought analysis in 126 designated study points of Turkey. The analyzed data includes monthly total precipitation values between March 2000 and February 2021, obtained from PERSIANN system (Precipitation Estimation from Remotely Sensed Information using Artificial Neural Networks). Monthly precipitation totals of these designated points were used as input parameters in the Drought Exceedance Probability Index (DEPI) which is a new drought analysis method. The analysis was conducted separately for the whole of Turkey from January to December. Moreover, the findings were compared with the Standardized Precipitation Index (SPI), a globally accepted and commonly used drought index, to measure the drought detection performance of DEPI. SPI was calculated for periods of 6, 12 and 24 months. Pearson correlation coefficients between drought values of SPI-6, SPI-12 and SPI-24 and DEPI results were calculated. The second part of the study includes possible trend of drought determined by the Mann-Kendall trend analysis method. Both DEPI and SPI results and trend analysis results were mapped and visualized with the help of ArcGIS package program. The highest correlation is between DEPI and SPI-12 with 0.75, while the lowest correlation is between DEPI and SPI-24 with a value of 0.62 . SPI monthly drought maps indicated the wettest months were January and February, while the driest months were March and July. Besides the DEPI monthly drought maps, the wettest months were October and November, while the driest months were May and June. The Mann-Kendall trend maps showed a significant increase in drought for summer.
\end{abstract}

Keywords: drought, hydrology, climate, Turkey, drought exceedance probability index.

\section{INTRODUCTION}

Drought is a normal, recurring natural disaster that can occasionally affect the struggle of human survival. Therefore, understanding drought characteristics might assist in developing better mitigation plans to a large extent (Mallenahalli, 2020). While different drought definitions have been developed in the literature, there is a widely popular quadruple classifica- 
tion. These are meteorological, agricultural, hydrological drought and socio-economic drought (Wilhite and Glantz, 1985). Among the drought types, it can be stated that meteorological drought is over-studied in the literature and accepted as a forerunner of all other drought events.

Meteorological drought deals entirely with weather conditions and is defined as a reduction in normal precipitation over the minimum recorded 30 -year precipitation series. Agricultural drought is considered to be the absence of sufficient soil moisture that causes wilting and plant death in agricultural areas. Even with adequate rainfall and water resources, agricultural drought might occur due to excessive use of water and insensible agricultural practices. Hydrological drought might also occur when the local population who benefit from water is high or rural activities and irrigation activities are undue, although the amount of precipitation and water in the reservoirs are sufficient (Topçu and Seçkin, 2016). Socio economic drought refers to droughts that adversely affect some social or economic function in life.

Drought impacts are evaluated by using drought indices in terms of severity, persistence, and spread. Some of these measures are; De Martonne Method (De Martonne, 1942), Palmer Drought Severity Index (Palmer, 1965), Decile Index (Gibbs and Maher, 1967), Aydeniz Method (Aydeniz, 1973), Erinç Method (Erinç, 1984), Standardized Precipitation Index (McKee et al., 1993), Aggregated Drought Index (Keyantash and Dracup, 2004), Reconnaissance Drought Index (Tsakiris and Vangelis, 2005), Streamflow Drought Index (Nalbantis, 2008), Actual Precipitation Index (API) (Şen and Almazroui, 2021). In addition to these indices, new drought monitoring indices continue to be developed.One of the newest index among these is the Drought Exceedance Probability Index (DEPI) developed by (Limones et al., 2022). DEPI is a modification of the ISSP (Indice Standardisé de Sécheresse Pluviométrique) developed by (Pita, 2000). Similar to other indices i.e. Standardized Precipitation Index (SPI) of (McKee et al., 1993) or the SPEI (Vicente-Serrano et al., 2010), DEPI is based on the calculation of cumulative monthly precipitation anomalies. On the other hand, each month's DEPI score shows the empirical probability of exceedance of the drought level experienced in that month (Limones et al., 2020).

The study aims to conduct periodic drought analysis of the period from January to December with the help of DEPI developed by (Limones et al., 2022) to monitor drought using monthly precipitation totals of 126 study points designated and located in Turkey. Precipitation data were obtained from the Precipitation Estimation from Remotely Sensed Information using Arti- ficial Neural Networks (PERSIANN) system, based on the location of the meteorological stations of the Turkish State Meteorological Service. The DEPI, an alternative drought index, was compared to SPI, a classical method in drought analysis, to determine its reliability. Mann-Kendall trend analysis was also utilized to obtain information about the course of the drought. DEPI, SPI and trend values were mapped with the help of ArcGIS package program (ESRI, 2012) so that the results could be seen as spatial rather than tabulated. This paper is organized as follows. The first section gives a brief introduction of study area, and then the research methodology is reviewed. In the next section, the results of the application of the selected method in Turkey are presented and conclusions are drawn in the final section.

\section{MATERIALS AND METHODS}

Turkey is located at the intersection of Asia and Europe in the Mediterranean Basin. As it is surrounded on three sides by the sea and its geographical features are unique, a wide variety of climate types can be observed. Although drought events are very common, rainy periods are also seen.The elevation, the distance to the sea and the direction of the mountains are effective in the formation of diverse climatic conditions. For this reason, June, July and August are poor months in the amount of precipitation throughout Turkey, except for the northeast of the Eastern region and Northeast regions. In particular, April is rainy across the country. Turkey has Mediterranean climate in the south and west coastal areas, the Black Sea climate to the north, and a continental climate in the inland Anatolian region and the Eastern part. Mediterranean climate is common in the Mediterranean, Aegean seas and southern Marmara. However, the characteristics of the Mediterranean climate in Marmara are more severe. It is hot and dry in summers, warm and rainy in winters. It is suitable for the cultivation of citrus fruits. Since it is common in southern latitudes, frost and snowfall are rare in the coastal belt. The Black Sea climate is typical in the Black Sea coasts and northern Marmara. It is rainy in all seasons. Summers are cool, and winters are warm on the coasts, cold and snowy at high altitudes. Precipitation is distributed throughout the year, and there is no dry season. The vegetation is steppe in the continental climate. Summers are hot and dry, and winters are cold and snowy (Atalay, 2011; Öztürk et al., 2017).

The distributions of the 126 study points selected for the study are demonstrated on the physical map of Turkey and shown in Figure 1. 


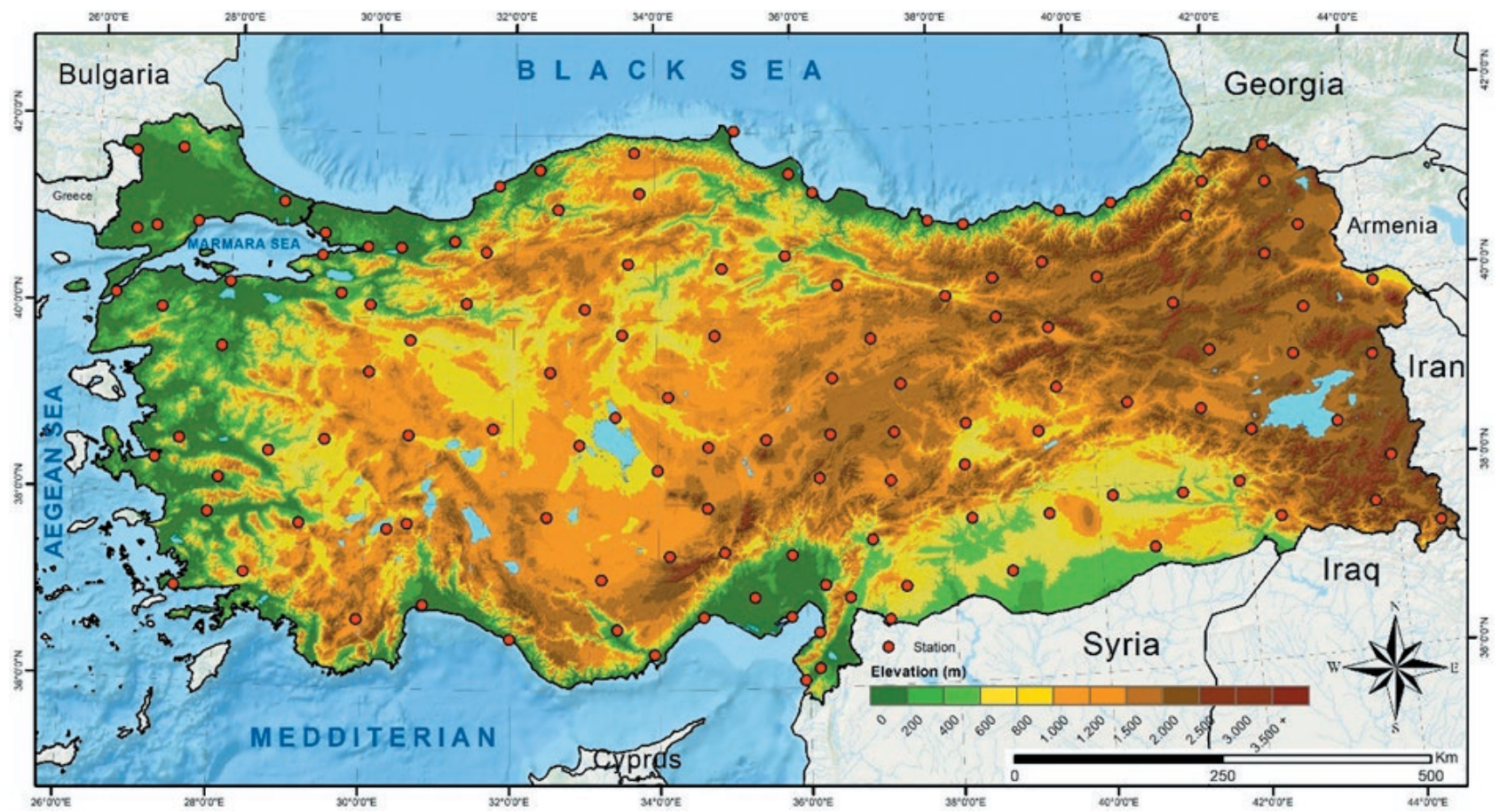

Fig. 1. Designated study points depicted on the physical map of Turkey.

The existing operational PERSIANN (Precipitation Estimation from Remotely Sensed Information Using Artificial Neural Networks) system uses neural network function classification / approximation procedures to calculate an estimate of the precipitation rate per $0.25^{\circ}$ x $0.25^{\circ}$ (about $625 \mathrm{~km}^{2}$ ) pixel of the infrared brightness temperature image provided by geostationary (fixedposition) satellites. The PERSIANN system was based on fixed infrared images and then expanded to include the use of both infrared and daytime visible images. In this study, the PERSIANN algorithm was utilized to create global precipitation based on geostationary longwave infrared images. The precipitation product consists of $50^{\circ} \mathrm{S}$ to $50^{\circ} \mathrm{N}$ globally. Model parameters are updated regularly using precipitation forecasts from low-orbit satellites (CHRS Data Portal, 2021).

The monthly precipitation values representing Turkey was obtained through the spatial average of 126 point precipitation data. Based on the areas of the designated points, the areal precipitation average was found. Accordingly, monthly precipitation values are depicted in Figure 2 from January to December for the 2000-2021 period.

When these graphs are examined, it can be monitored in which year and in which month the amount of precipitation decreases or increases. Figure 2 illustrates that the highest monthly precipitation average was measured in January 2007. The lowest average precipitation is in August. It was calculated for the January and February period for 2001-2021, and for the March and December period for 2000-2020. Because the PERSIANN system has made measurements between these periods until now, the determined periods are based on the existing data.

Detailed information about this system can be accessed from (Hsu et al., 1997; Hsu et al., 1999, 2000, 2002; Sorooshian et al., 2000, 2002; Sorooshian et al., 2014; Nguyen et al., 2019).Monthly precipitation point totals for March 2000 and February 2021 were obtained from the PERSIANN system.

DEPI (Limones et al., 2022) and SPI (McKee et al., 1993) were used in this study. The SPI method is not elaborated in this study since there are several studies about SPI worldwide. SPI is a meteorological drought analysis method that uses only the precipitation parameter. The SPI is obtained by dividing the difference from average precipitation over the specified period by the standard deviation. If the SPI value obtained is " 0 " and above, it represents wet conditions, and if it is below " 0 ", it indicates drought conditions. Calculations for 3, 6, 9, 12 , 24-month periods can be performed to examine the effect of drought on water resources in different periods. 3,6 , and 9 months-long samples examine the effect of precipitation deficiency on soil moisture in the short and medium term, while 12 months or longer time intervals reveal the impact of drought on water resources such 


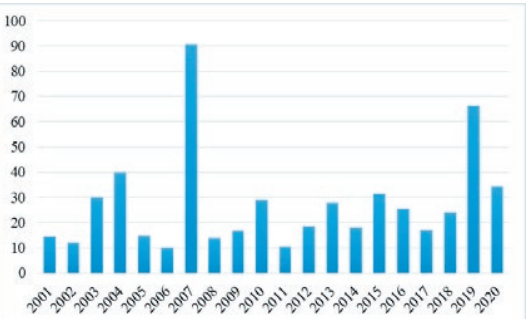

JANUARY

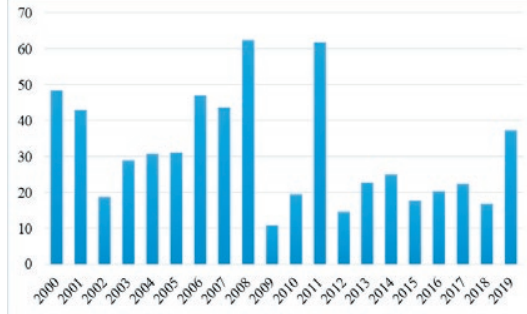

APRIL

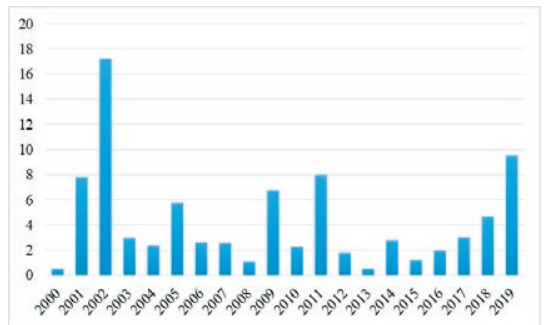

JULY

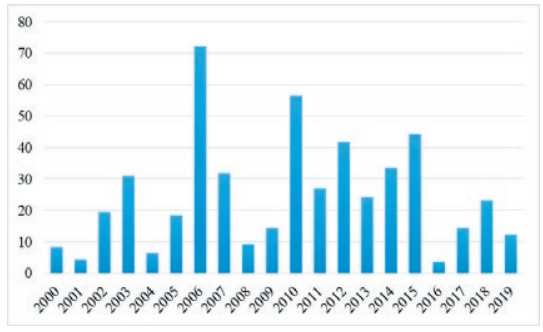

OCTOBER

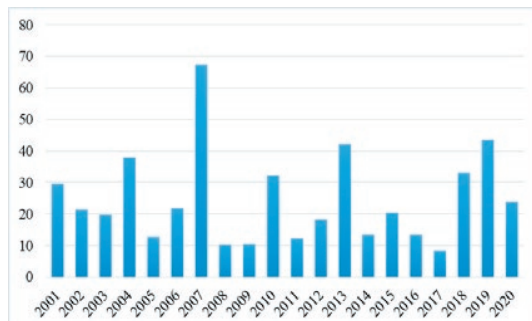

FEBRUARY

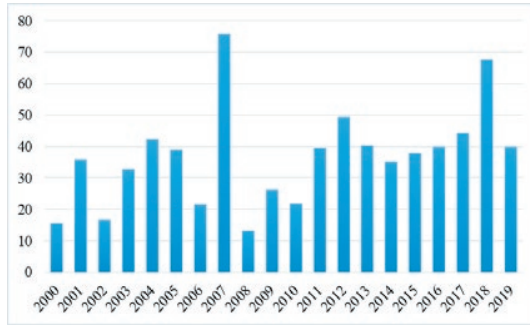

MAY

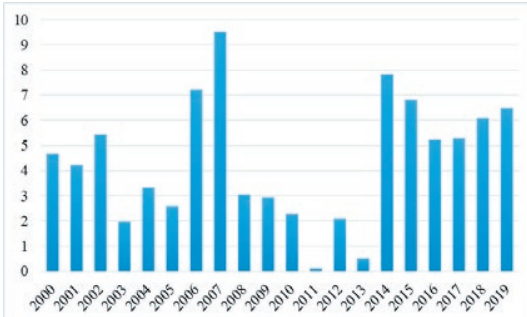

AUGUST

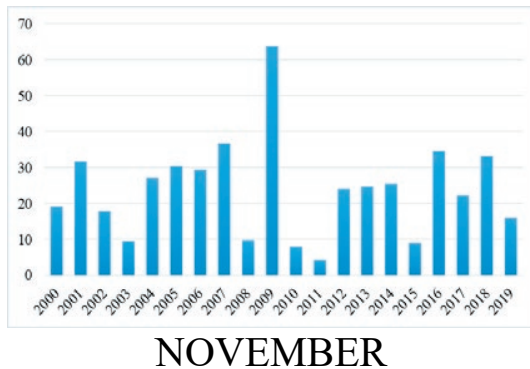

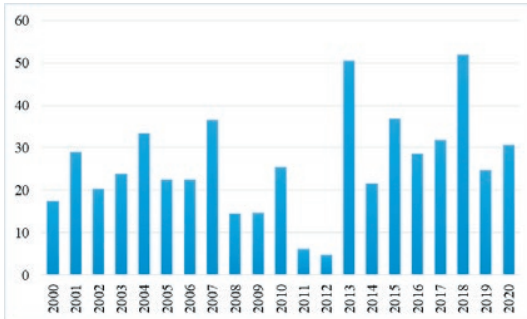

MARCH

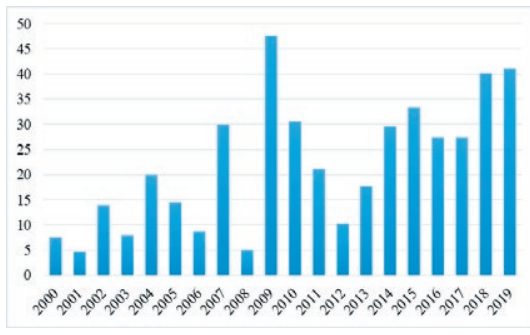

JUNE

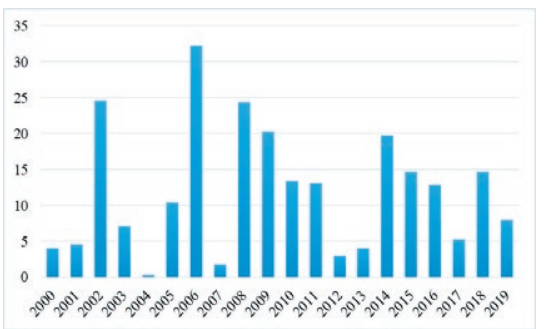

SEPTEMBER

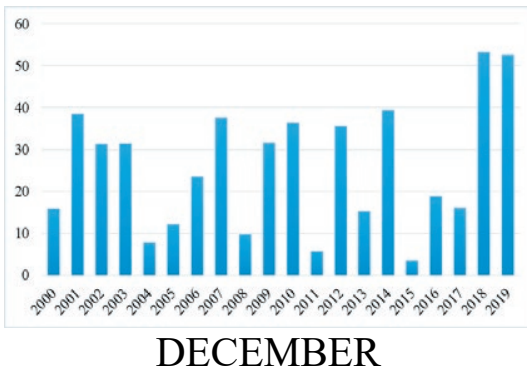

Fig. 2. Turkey's monthly precipitation values for period of 2000-2021 (mm).

as reservoirs. The 6, 12, and 24-month long SPI values examining drought in the short, medium and long term were analyzed in this study. SPI calculation steps are presented in detail in (McKee et al., 1993) and Topçu and Seçkin's (2016) studies. Drought categories with SPI values are available in Table 1.

DEPI calculation is carried out in the following consecutive stages: In the first step, the precipitation anomalies $(A P)$ of each month of the series are calculated from the following expression:

$A P_{i}=P_{i}-P_{M E D i}$
$P_{M E D i}=$ Median precipitation of the month $\mathrm{i}$ for the whole study period.

An example of the calculation of these monthly anomalies is presented in Figure 3 and Figure 4.

As it is considered more appropriate than the average for highly variable meteorological regimes, the index utilized the median to identify surpluses and deficits (Pita, 2000). Second, cumulative precipitation anomalies are identified from the first month of the series. After a negative anomaly is found, a dry sequence begins, and then the accumulation is restarted in that particular month. Following this restart, month-to-month addition of anomalies proceeds. After ensuing accumulations, as 
Table 1. SPI drought classifications according to SPI values (Mckee et al., 1993).

\begin{tabular}{lc}
\hline SPI values & Drought severity level \\
\hline$>0.00$ & Wet conditions \\
-0.99 to 0.00 & Mild drought \\
-1.00 to -1.49 & Moderate drought \\
-1.50 to -1.99 & Severe drought \\
$<-2.00$ & Extreme drought \\
\hline
\end{tabular}

soon as the cumulative anomalies become positive again, the dry run ends. In this wet run, anomalies carried on adding until a new negative precipitation anomaly is found. As expected, at that point a new dry sequence starts, which is estimated by using the same method. The methodology consists of continuous addition of surpluses that allows for precise anomaly prioritization and stops in the condition of negative anomaly. Thus, the evaluation of this second step match with the expression:

$A P A c_{1}=A P_{1}$,

$A P A c_{1}=\sum_{j=r}^{i} A P_{1} \quad i>1$

where $A P A c_{1}=$ precipitation cumulative anomaly of the
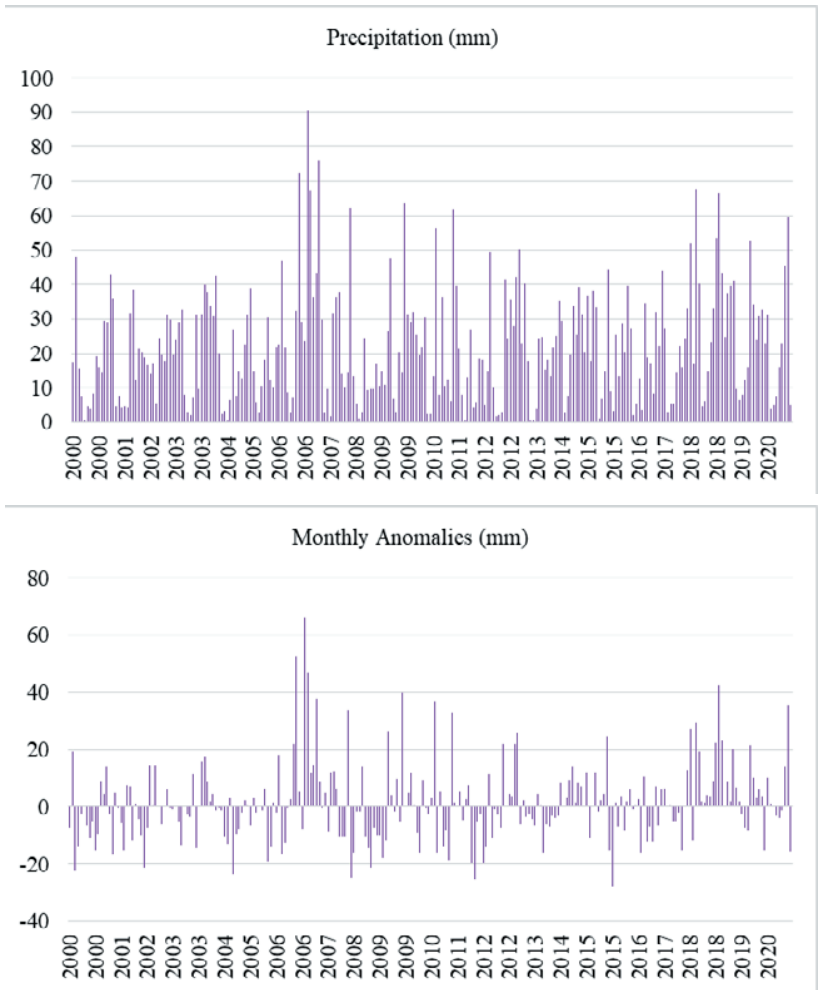

Fig. 3. Process of implementing the Drought Exceedance Probability Index (DEPI) in the precipitation series of Turkey, 2000-2021. month $i ; r=$ the value marking the start of the dry run and follows the expression:

$r=\max \left\{k: 1 \leq k \leq i, A P_{k}<0, A P A c_{k-1} \geq 0\right\}$, k: parameter from 1 to $i$ to determine which month the drought started.

It is critical to mention that if $A P_{1}<0$ and $A P A c_{k-1} \geq$ 0 , then $r=i$ and, as a result $A P A c_{1}=A P_{1}$, specifying the beginning of a new dry series. In sum, in the third step, it is required to sort the series of cumulative precipitation anomalies identified in the previous stage from lowest to highest, i.e. from the months with the largest negative cumulative anomalies, or deficits, to the months with the largest positive ones, or surpluses. Following the steps outlined above is required to obtain the empirical probabilities of exceedance matching with each month of the series. After the sorting process has been performed, the formulation of DEPI requires calculating the probability of exceeding the detected event each month by utilizing the plotting positions method developed by (Weibull, 1939):

Pexced $_{A P A C i}=D_{E P I}=M_{A P A C i} /(n+1)$

where; Pexced $_{A P A C i}=$ empirical probability of exceedance of the month $i$, namely, the DEPI of the month $i$; $M_{A P A C i}$
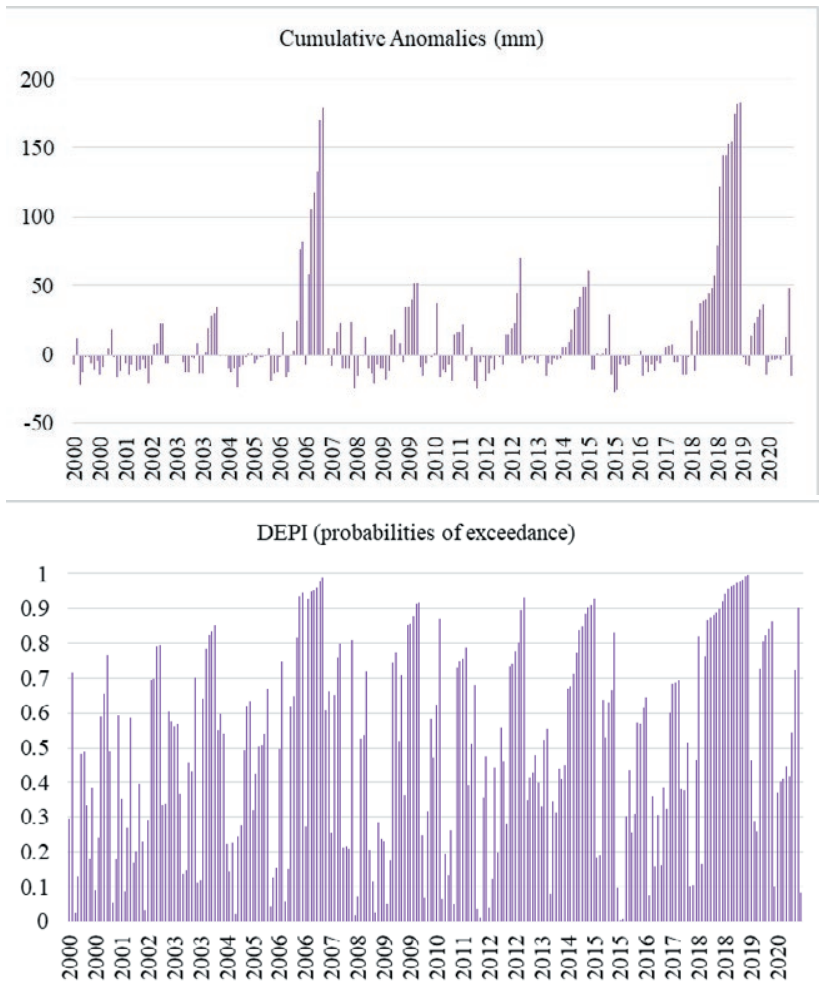

Fig. 4. Process of implementing the Drought Exceedance Probability Index (DEPI) in the precipitation series of Turkey, 2000-2021 (Continue). 
Table 2. DEPI drought classifications according to DEPI values (Limones et al., 2022).

\begin{tabular}{lccc}
\hline $\begin{array}{l}\text { DEPI values } \\
\text { (probabilities of } \\
\text { exceedance) }\end{array}$ & $\begin{array}{c}\text { Drought severity } \\
\text { level }\end{array}$ & $\begin{array}{c}\text { \% months of a series } \\
\text { within the interval }\end{array}$ & $\begin{array}{c}\text { Return } \\
\text { period } \\
\text { (years) }\end{array}$ \\
\hline DEPI $\geq 0.5$ & Wet conditions & 50 & 2 \\
$0.5>\mathrm{DEPI} \geq 0.16$ & Mild drought & 34 & 6 \\
$0.16>\mathrm{DEPI} \geq 0.07$ & Moderate drought & 9 & 15 \\
$0.07>\mathrm{DEPI} \geq 0.02$ & Severe drought & 5 & 20 \\
DEPI $<0.02$ & Extreme drought & 2 & 50 \\
\hline
\end{tabular}

$=$ position of the precipitation cumulative anomaly of the month in the sorted series, from lowest to highest cumulative anomaly or largest observed deficit, $n=$ total number of months in the series. Thus, the DEPI for a given month is exactly the probability of exceedance ascribed to its cumulative rainfall anomaly, determined as described above. The probability values not only contains an estimate of the hazard but also with DEPI values below 0.5 indicates significant accumulation of anomalies (not likely to be exceeded). So droughts are becoming more severe as they approach 0 . The significance of the index and its further advances over other similar ones, is that it restarts with measurement of cumulative anomalies whenever a new dry month $\left(A P_{1}\right.$ $<0$ ) arises within a surplus period (with $A P A c_{i-1} \geq 0$ ). This guarantees the proper identification of dry runs of different lengths from a single calculation of the index. DEPI drought classification values are seen in Table 2.

In this study, trend analysis was carried out to determine whether drought is decreasing or increasing over the years with the calculated index values. Drought index values were analyzed with Mann-Kendall trend analysis. Mann-Kendall test, null hypothesis H0 against xi observations randomly sorted over time, the alternative hypothesis that has an increasing or decreasing monotonic course of observations was applied to test H1. The data are treated as sequential time series. Each data value is compared with the consequent value. In the present paper, $5 \%$ level of significance is used to check increasing or decreasing trend. Since the Mann-Kendall method is a frequently used trend analysis, there are plenty of annotated sources in the literature. MAKESENS (Salmi et al., 2002) excel macro was also used.

\section{RESULTS AND DISCUSSION}

Before mapping, monthly DEPI values were graphed for data-available periods. Figure 5 highlights the annual change of DEPI values by months.
A DEPI value of 0.5 , which indicates the boundary between dry and wet conditions, is indicated by a red line on the graphs. It can be asserted that the closer the DEPI values to 0 , the more severe drought is experienced. The years when DEPI exceeded 0.5 were observed as wet years. According to the results, while the lowest DEPI value was observed in 2009 for January, the highest DEPI value was measured in 2019. There was a dry period between 2011 and 2014. DEPI values for February were similar to January. However, the DEPI values dropped sharply to drought values after 2020. The lowest DEPI value was measured in 2009 and 2012, while the highest was observed in 2007 and 2019 for March. A dry period was observed between the years 2008-2013 for April. While the lowest DEPI was measure in 2009, DEPI values started to decrease as of 2019 for May. The lowest DEPI values were measured in 2002, 2006, 2009 and 2012 for June. A dry period was observed between 2000 and 2004. The month of July draws a similar trend to June. The wet period was between 2017 and 2020. The lowest DEPI was measured in August in 2012, a dry period was observed between 2000 and 2006 in September, October, November and December. The DEPI values started to decrease to dry values after 2019 in December. Drought values for 6, 12 and 24 months were calculated with SPI. The Pearson correlation method was used to determine whether the findings were compatible with DEPI. It was examined whether DEPI increased (decreases) while SPI values increase (decrease) with this method in a sequence. The correlation between SPI and DEPI was visually mapped for Turkey through the Pearson correlation coefficient values SPI6-DEPI, SPI12-DEPI and SPI24-DEPI. Pearson correlation coefficient maps for SPI6-DEPI, SPI12DEPI and SPI24-DEPI on Turkey are available in Figure 6, Figure 7 and Figure 8, respectively.

The Pearson correlation coefficient values ranged between 0.50 and 0.87 . The average correlation coefficient values were $0.73,0.75$ and 0.62 for SPI6-DEPI, SPI12-DEPI and SPI24-DEPI. Figure 6 demonstrates that the lowest correlation value was observed in the inner parts of Eastern Anatolia, while the highest correlation was in the west of Southeastern Anatolia. Besides, Figure 7 indicates that the lowest correlation was found for the east of the Eastern Anatolia Region and the highest in the west of the Marmara Region and the Aegean Region. Moreover, Figure 8 illustrates that the lowest parallelism was observed for the Southeast Anatolia Region and the inner parts of the Central Anatolia Region, while the highest was for the Aegean coasts and Central Mediterranean Region. These results revealed that the highest correlation was between SPI12 and DEPI. 


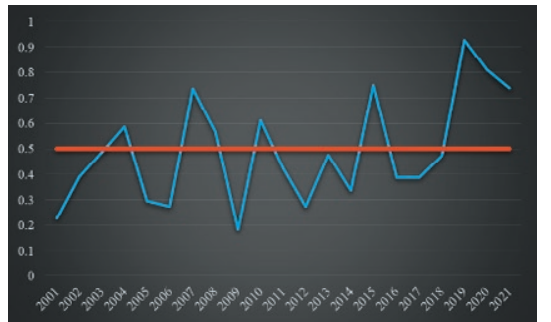

JANUARY

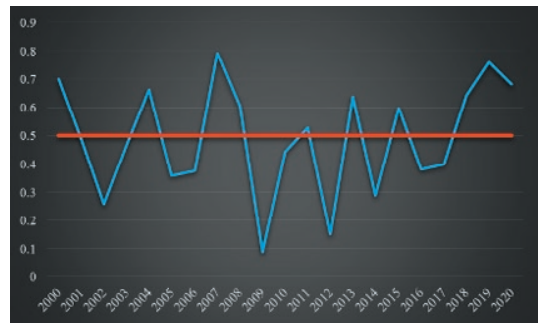

APRIL

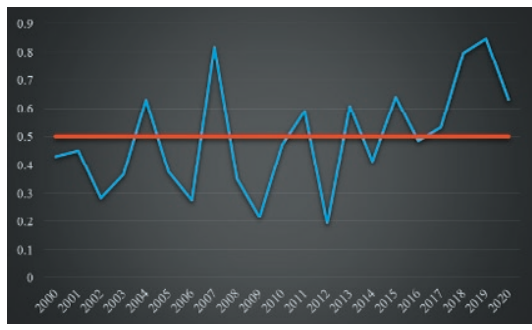

JULY

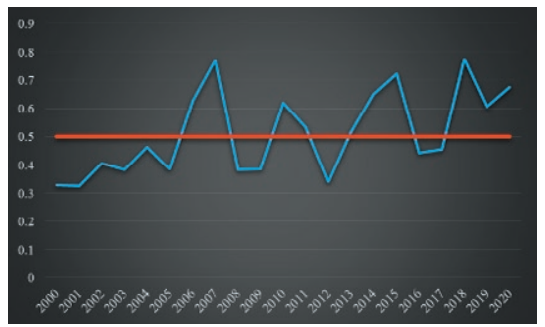

OCTOBER

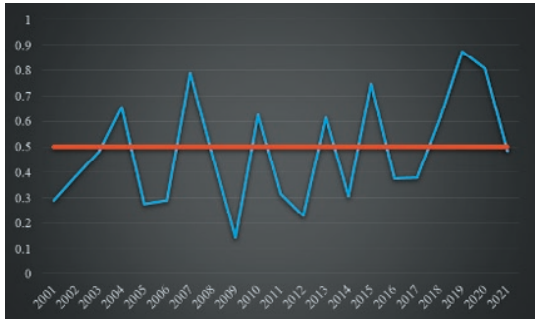

FEBRUARY

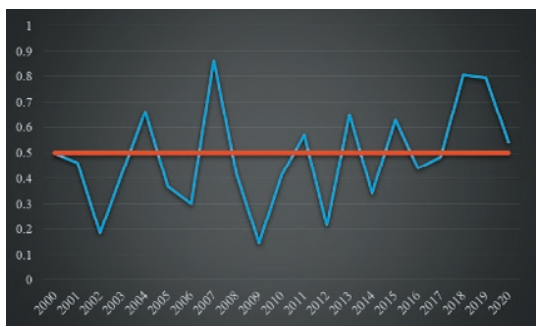

MAY

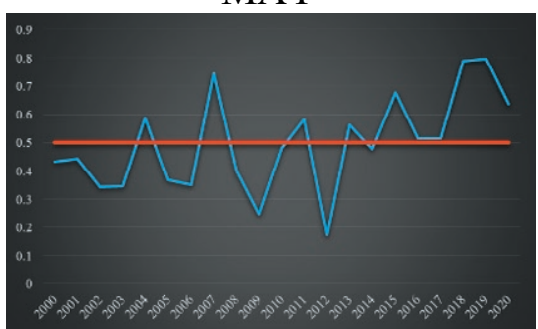

AUGUST

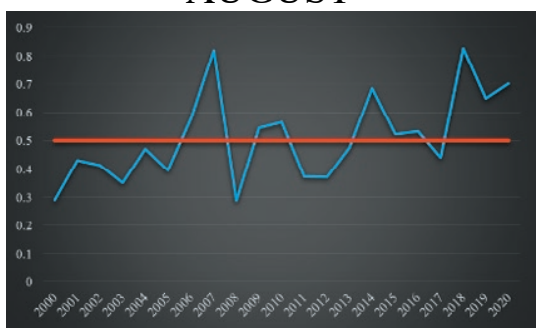

NOVEMBER

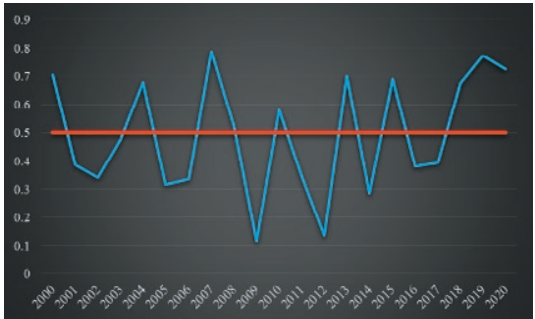

MARCH

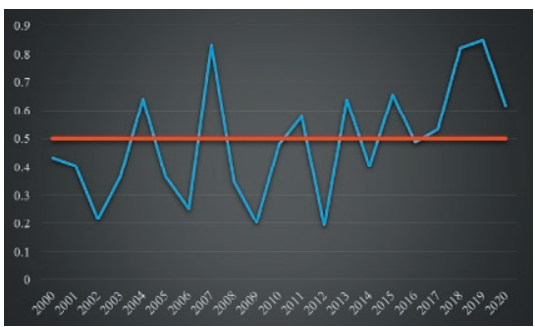

JUNE

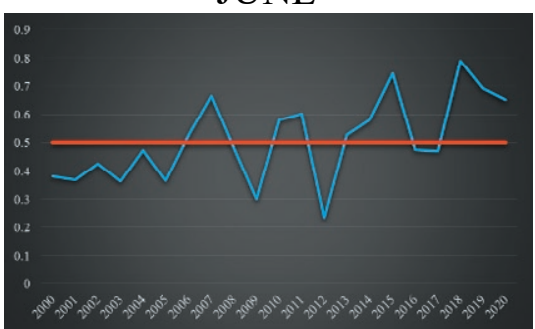

SEPTEMBER

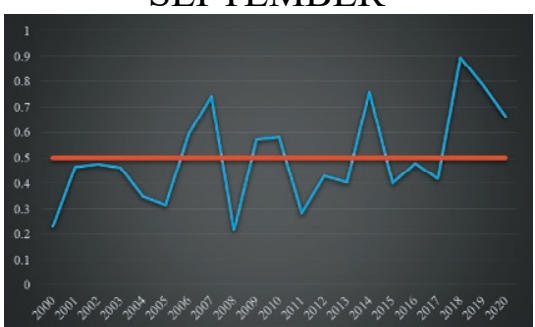

DECEMBER

Fig. 5. Yearly change of monthly DEPI values in Turkey.

After the DEPI and SPI values were obtained, the mapping was performed using the Inverse Distance Weighted (IDW) interpolation method. A specific color scale has been determined so that the drought classification based on DEPI and SPI values can be distinguished on maps. The color scales corresponding to DEPI and SPI values is located at the end of Figure 9. It is mapped for 2001-2021 period for January and February, and for March and December 2000-2020 period, where PERSIANN precipitation data can be obtained.

Thus, the SPI12 drought values, which have the highest correlation with DEPI, were mapped. Different SPI and DEPI calculation methods have led to a difference in the drought assessment in Turkey, especially for some months. For reader-friendlier maps, the same colors were used in the SPI and DEPI drought classifications. Monthly SPI12 and DEPI maps were collaged together to reveal this difference in the best way.

These maps may indicate that the whole of Turkey is in the wet and mild drought category. The drought and wetness vary spatially by month. Another reason for the monthly drought analysis in this study is that the changes in the months cause seasonal changes. This is of vital importance especially for issues that require water resources planning such as dams and hydroelectric power plants.

The SPI12 map for January in Figure 9 indicates that wet conditions prevail throughout the country, except for 


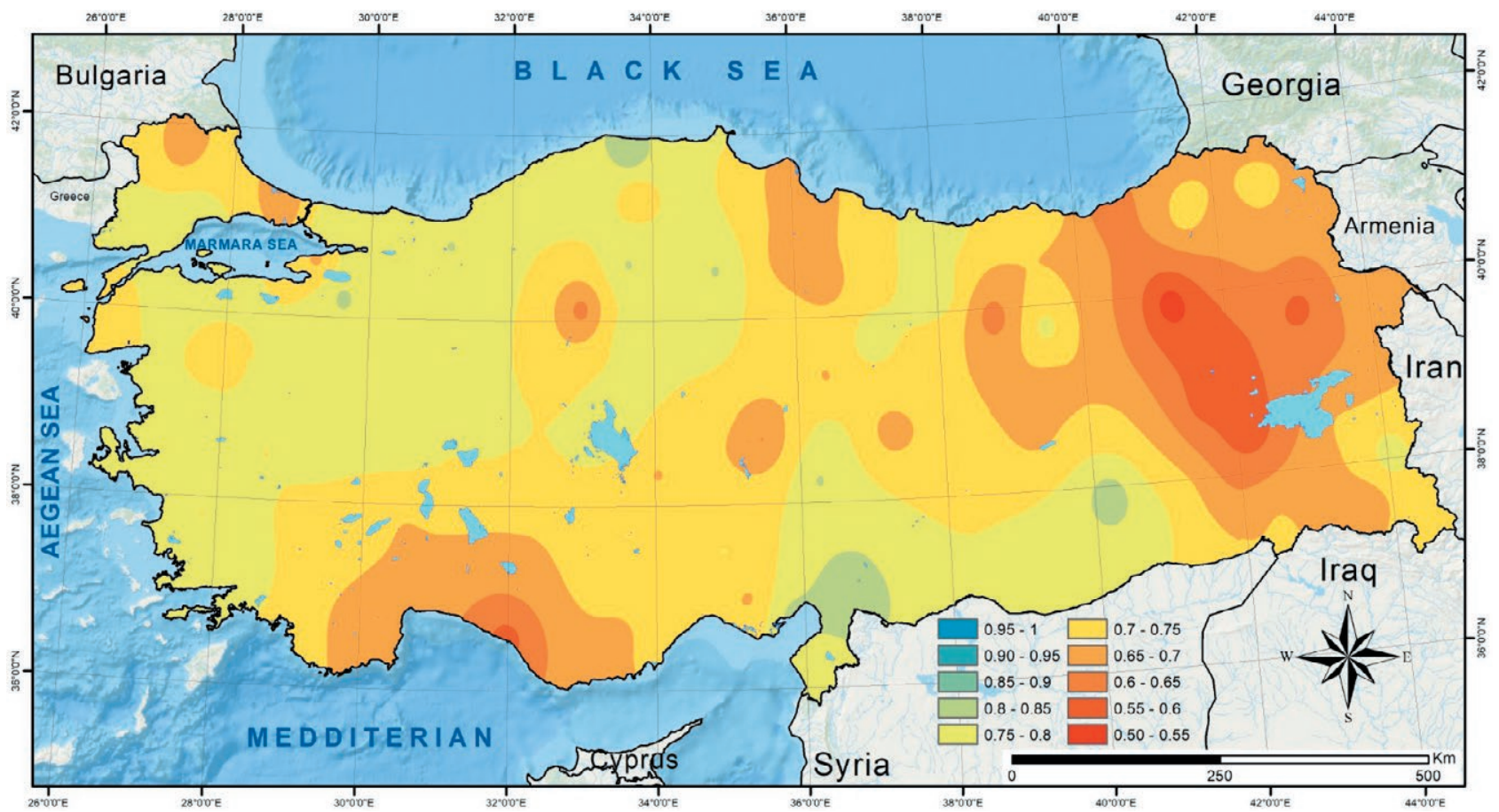

Fig. 6. Correlation coefficient map of SPI6-DEPI for Turkey.

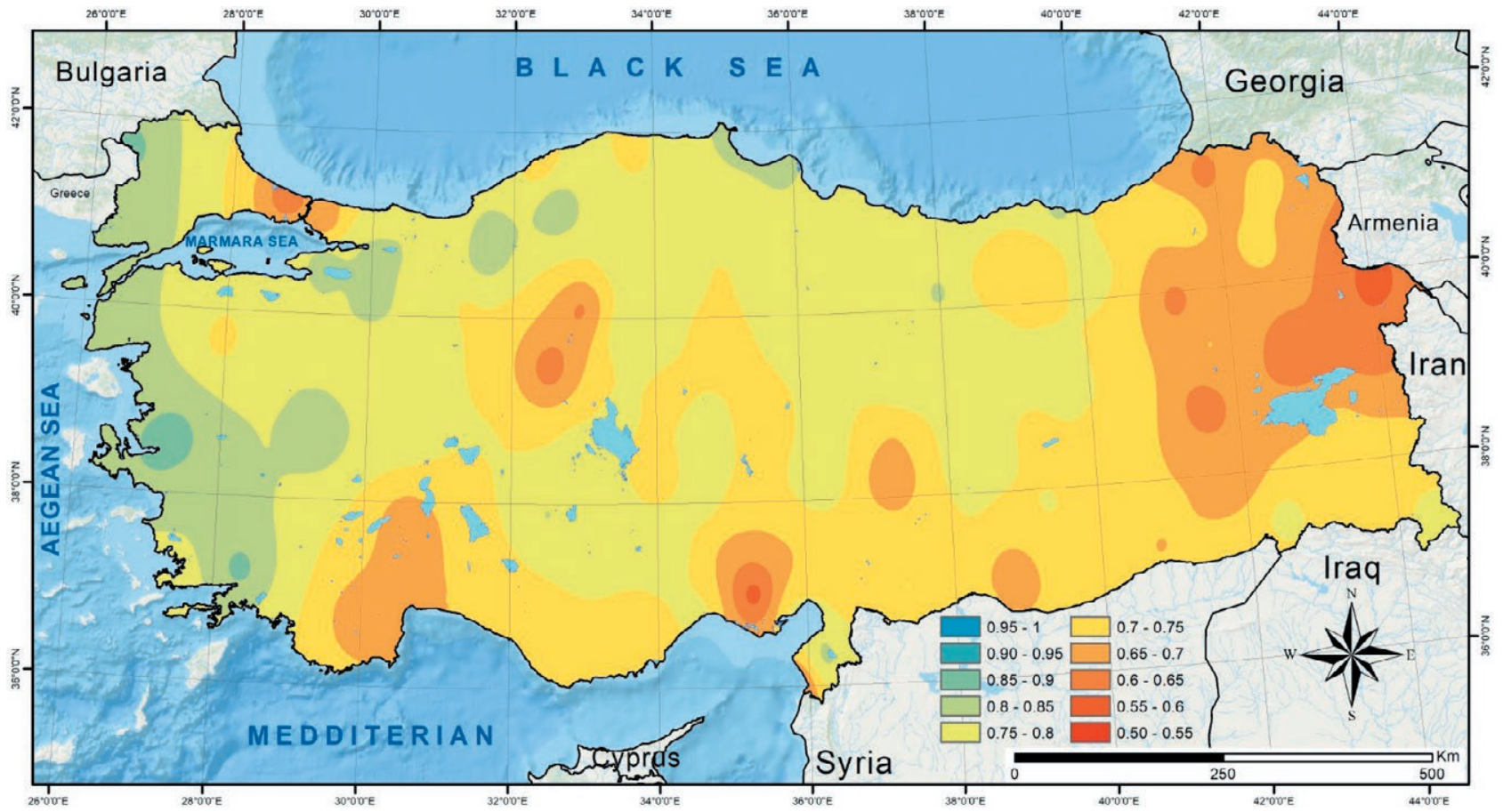

Fig. 7. Correlation coefficient map of SPI12-DEPI for Turkey.

the Southeastern Anatolia Region. However, the January DEPI map shows mild drought conditions are common except for the inner parts of the Inner Aegean,
Southeastern Anatolia and Eastern Anatolia. The February maps exhibit similar conditions with January. The western parts of the country are wet in SPI12 for March, 


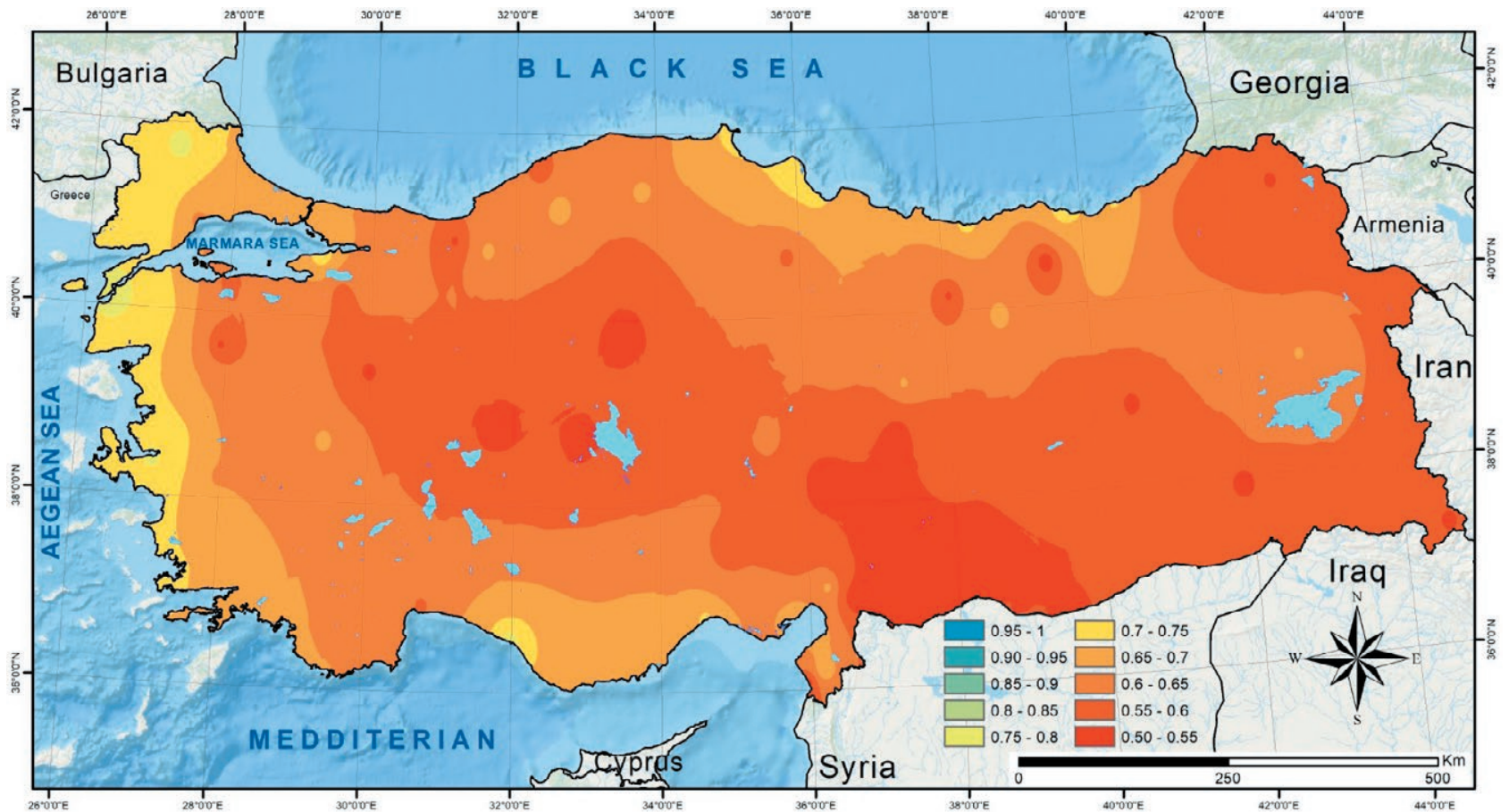

Fig. 8. Correlation coefficient map of SPI24-DEPI for Turkey.

while the other parts are mildly dry. The DEPI map indicates mild drought in the country except for the western Mediterranean and eastern Anatolia regions. Besides, the SPI12 map for April illustrates wet conditions except for the eastern Mediterranean and southeast Anatolia, while the DEPI map shows mild drought except for the south and interior parts. Almost half of the country is wet in SPI12, while some parts are wet in DEPI for May. The eastern Mediterranean, southeast Anatolia and the west of eastern Anatolia are wet in SPI12 for May, as it is wet in DEPI although similar to the SPI12 map, the inner parts of the west of the country are also mildly dry. September was similar to August in SPI12 as a mild drought was observed in the country's east by DEPI. October was similar to September in SPI12, while a mild drought was dominant in the interior parts of the eastern Black Sea region in DEPI. November SPI12 was similar to September. However, wet conditions are observed in DEPI except for the inner and western regions. December was similar to November in regards to DEPI, but the mild drought area was larger.

The drought detection success of DEPI is at a level that can be considered adequate after the comparison with SPI12. Correlation rates also support this. While SPI12 described most of the country through wet conditions, mild drought was presented in DEPI. Wet and mild drought conditions were measured by the precipi- tation amount calculated by the PERSIANN system and the methods used in Turkey. The results are entirely dependent on the reliability of the PERSIANN system. The mild drought occurs in cases where there is little or no precipitation, while wet conditions are classified as cases where precipitation is higher than the average. However, the lack of precipitation in a region does not mean that there is a drought, or very high precipitation does not mean that there is no drought. Because it is necessary to examine the long-term (min. 30 years) statistical precipitation series of that region. In the summer months, a large number of " 0 " values are encountered in the monthly precipitation total series. It should also be taken into account that only 20 years of precipitation data is used. Sudden and heavy rains as a result of the change of seasons can cause different results in the drought calculation.

Another analysis conducted in this study is the Mann-Kendall trend analysis. These analysis results are also visually mapped in Figure 10.

Only the trend maps of the DEPI values were provided since the correlation (reciprocal increase and decrease) between SPI12 and DEPI at an adequate level, and the Mann-Kendall trend analysis looks at the increase and decrease in drought values. The color scale and significance levels corresponding to these colors and whether the trend is decreasing or 

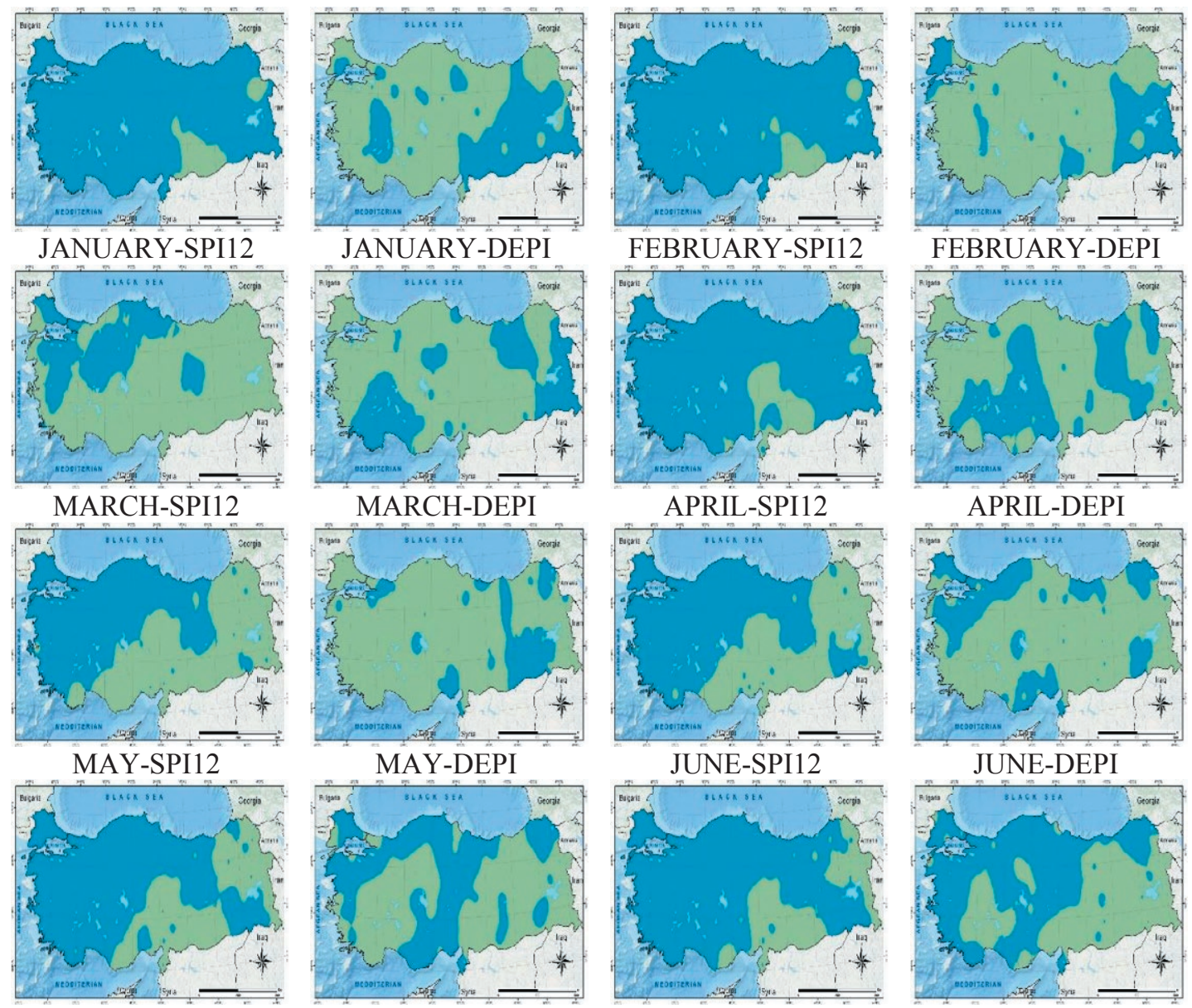

APRIL-DEPI

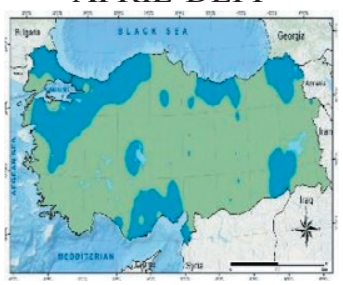

JUNE-SPI12
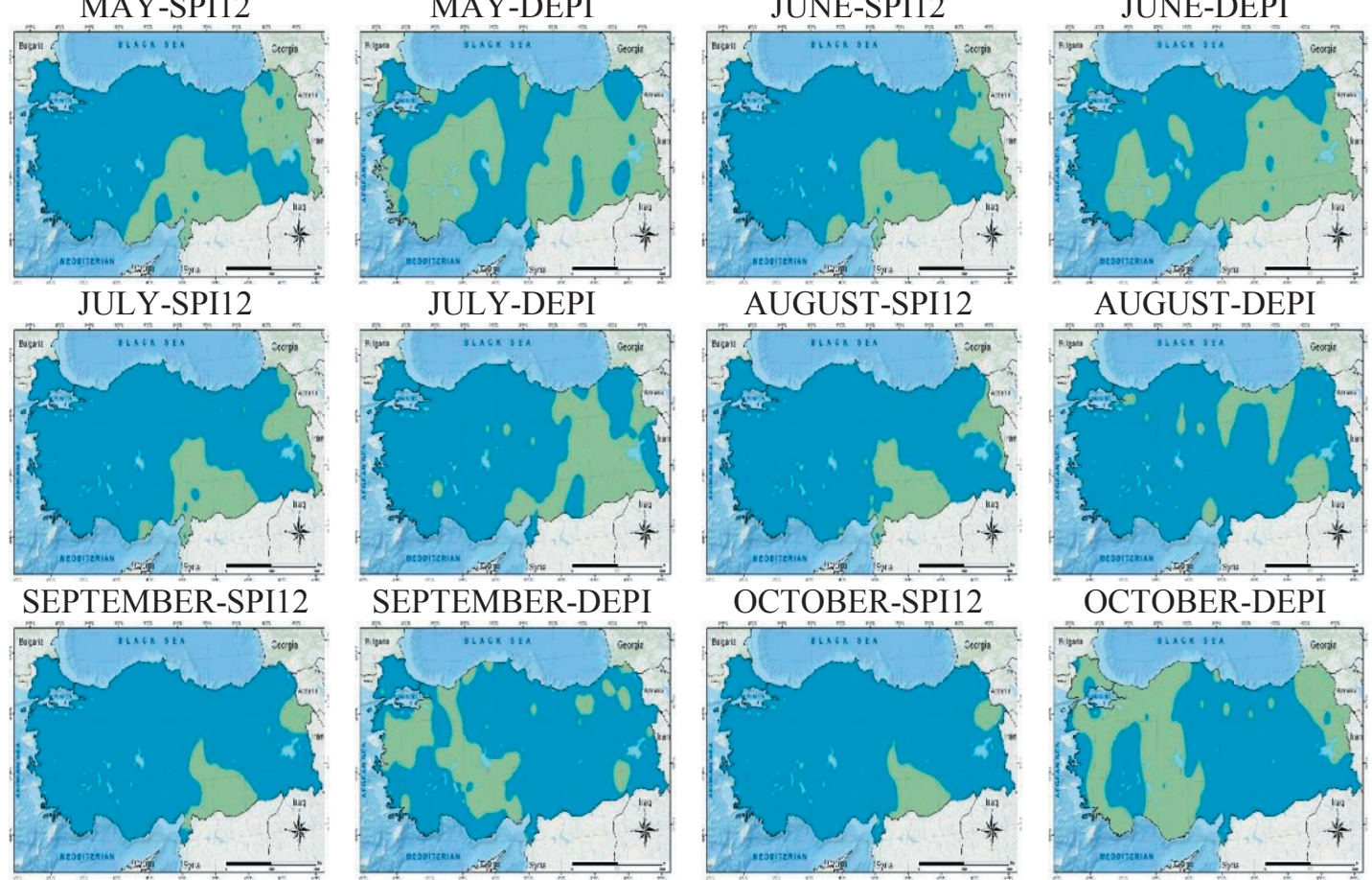

NOVEMBER-SPI12
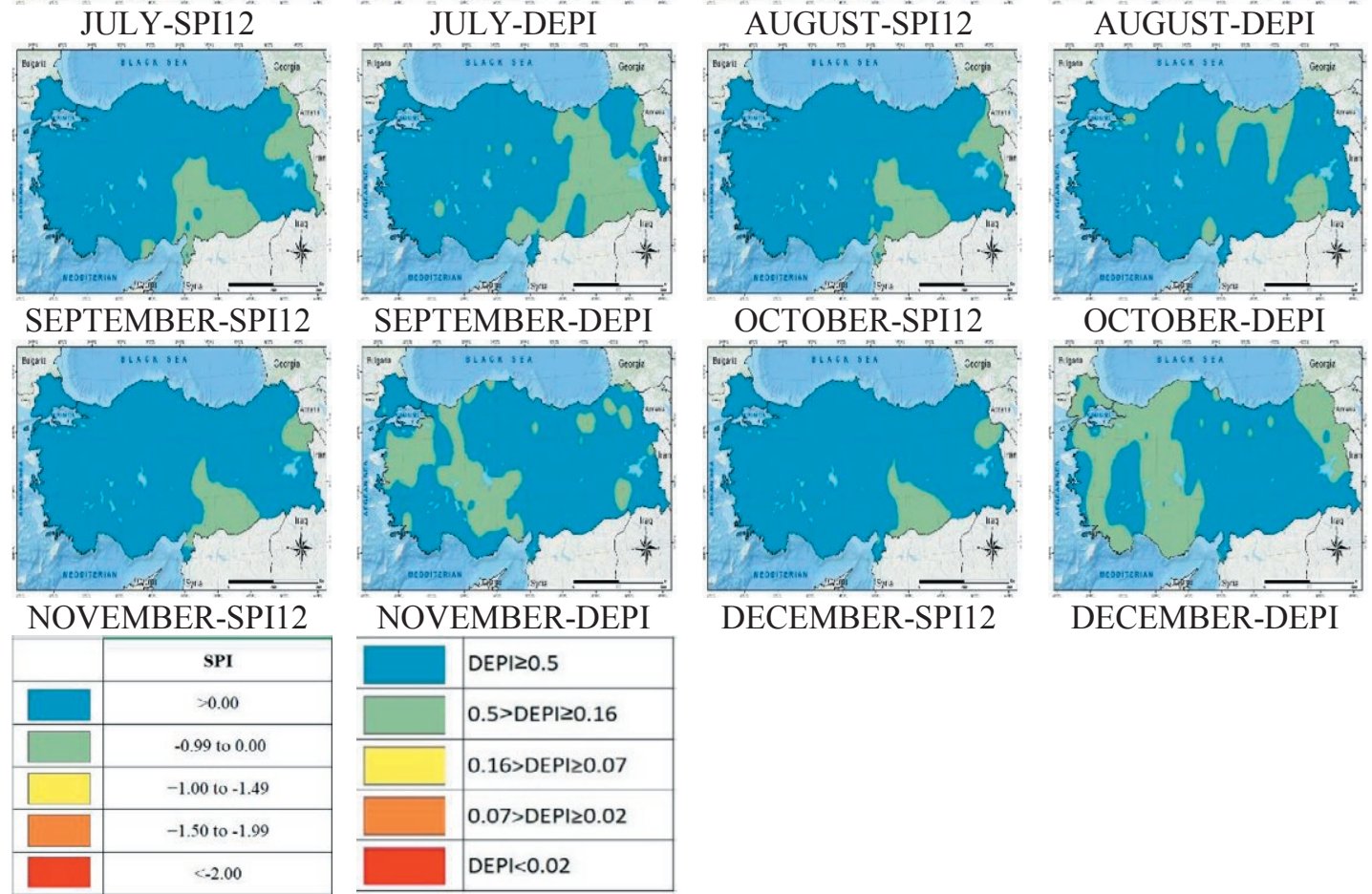

DECEMBER-DEPI

Fig. 9. Comparison of Turkey's monthly SPI-12 and DEPI maps. 

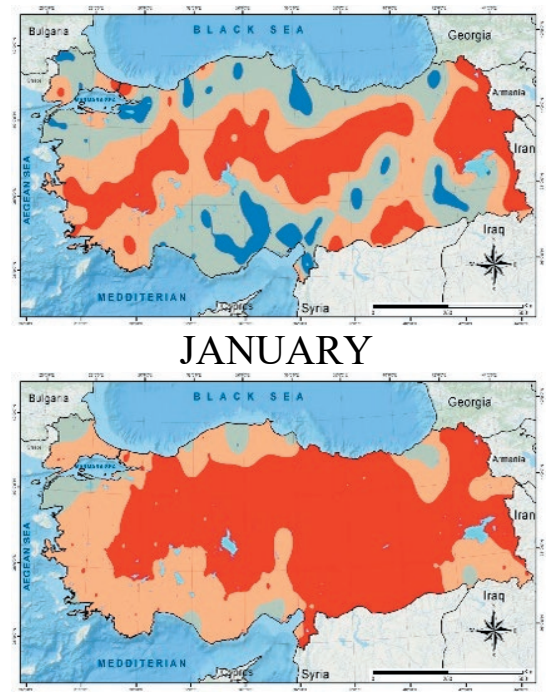

APRIL

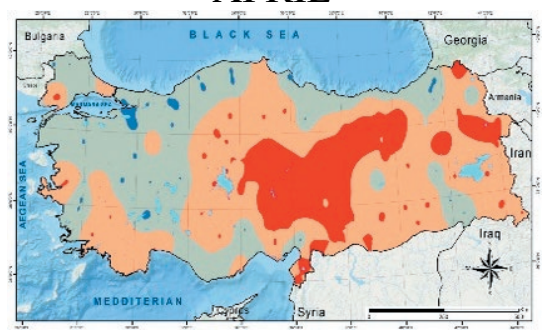

JULY

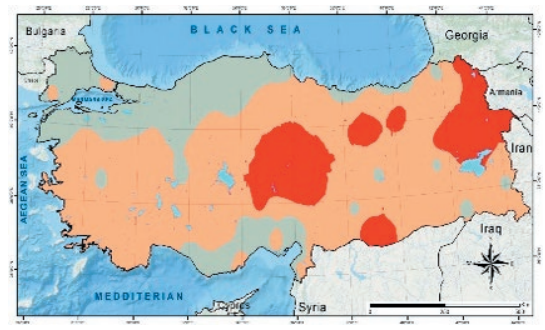

OCTOBER

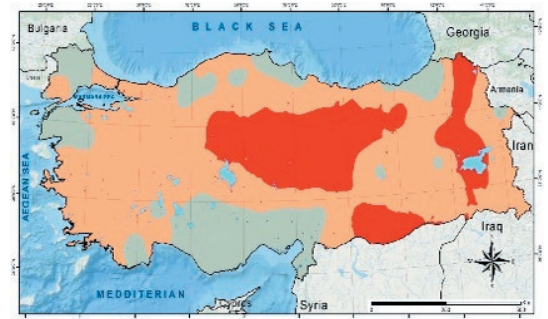

FEBRUARY

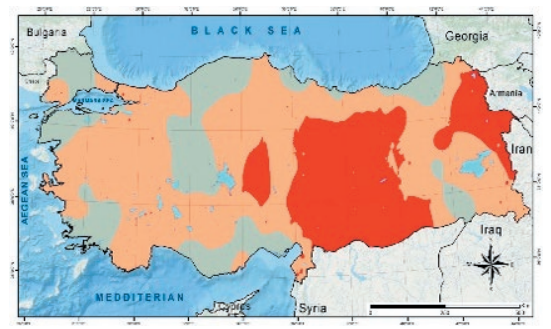

MAY

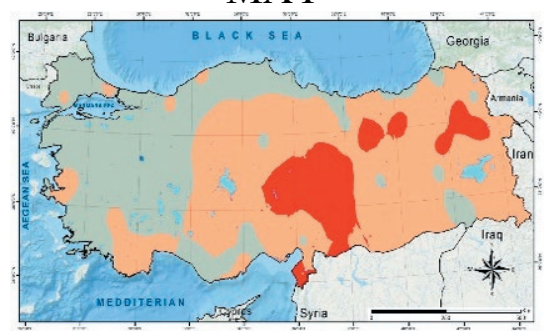

AUGUST

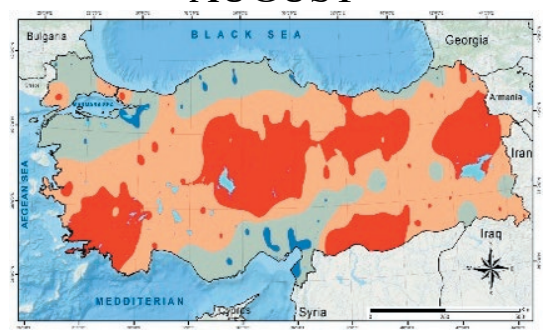

NOVEMBER

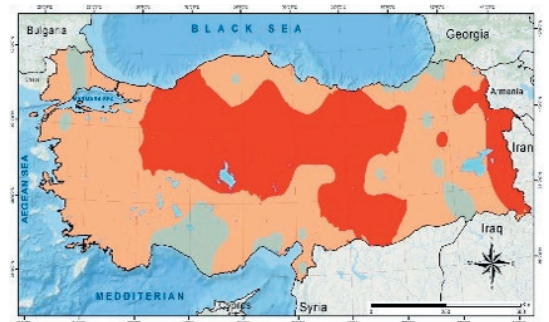

MARCH

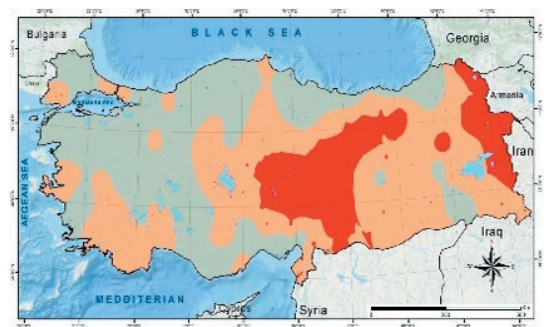

JUNE

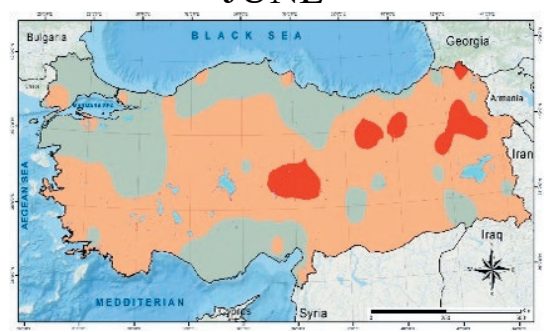

SEPTEMBER

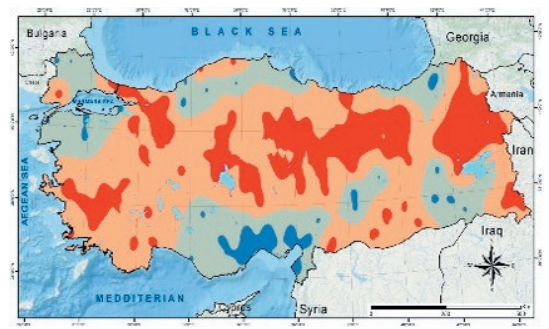

DECEMBER

Significant Increasing Trend

Significant Decreasing Trend

Insignificant Increasing Trend

Insignificant Decreasing Trend

Fig. 10.Monthly trend analysis maps of Turkey's DEPI values.

increasing are given at the end of Figure 10. Mapping was performed through 4 different trends: significant increasing trend, significant decreasing trend, insignificant increasing trend and insignificant decreasing trend. As the DEPI values change between " 0 " and "1", the increasing trend represents the decrease in drought conditions, and the decreasing trend represents the increase.

As the trend analysis maps in Figure 10 shows a significant decreasing trend was observed in the northern and southern regions, while a significant increasing trend is observed for certain areas in January. Besides, 
an insignificant decreasing trend was observed in the inner parts during February. Similar conditions to February was observed in March, while the insignificant trend spread to more areas. An insignificant decreasing trend was measured throughout the country, excluding the Aegean and Mediterranean regions, in April. Another insignificant decreasing trend was detected in the east of the country in May. However, a significant decreasing trend was observed, especially in the western parts of the country, in June, July and August. Another significant decreasing trend was detected in the Central Mediterranean, Marmara, Central and Western Black Sea sections in September. A significant decreasing trend is observed, especially in the northwest of the country, in October. A significant increasing trend was observed in a limited area within the Eastern Mediterranean in November and December. Except for the regions above in the country, an insignificant decreasing trend was measured.

Drought analysis are made based on the values of long annual climatic parameters (precipitation, temperature, humidity, etc.) for the past period. The longer the climatic parameter series are, the more accurate results can be obtained in terms of the drought of a region. Today, automatic or manual meteorological observation stations cannot be installed everywhere because of lack of financial resources or unsuitable land. However, satellite remote sensing methods such as PERSIANN fill this gap. High-resolution measurements in a wide range of areas are reassuring. Satellite-sourced data were also used in our study i.e. Turkey drought assessment study. Moreover, since they recently started collecting data (about 20 years), the obtained data series quite short. It is recommended to have a minimum of 30 years of data in meteorological drought assessment indexes, such as SPI, which use monthly precipitation as data. Otherwise, it is stated that the reliability of the results might decrease.

\section{CONCLUSIONS}

Drought is a climatic catastrophe that can be seen all over the world and in any type of climate, causing deep wounds on the ecosystem. Today, with the help of developing technology, satellite data, and complex mathematical algorithms, the area and duration of the drought can be easily determined.

This drought analysis study was carried out in Turkey, one of the countries most affected by drought and global climate change, which has increased its impact in recent years. The quantity of hot days has been increasing in Turkey. An average temperature of $14.7^{\circ} \mathrm{C}$ is measured in Turkey for 2019 , as this is $1.2{ }^{\circ} \mathrm{C}$ higher than the normal $1981-2010\left(13.5^{\circ} \mathrm{C}\right)$ temperature. Moreover, 2018 was the second while2019 was the fourth hottest year since 1971 (MGM, 2019).

Instead of precipitation data obtained from meteorological stations observing at ground level, it was preferred to use satellite-sourced precipitation data. Because it is thought that the use of satellite data might become widespread in the future. With the help of spatial mapping, the use of which has increased frequently in recent years, the country's month-specific drought situation and drought trends have been visualized. The correlation coefficient values between SPI12 and DEPI, available in the drought maps, suggest that DEPI gives similar results with SPI, which is a classical and common method, especially for August, September, October and November. However, using only precipitation data is the only limitation of this study. Because the more the other parameters of the hydrological cycle are examined, the more definite climatic drought can be reached.

The findings indicate that there was a significant decrease in drought for certain parts of the country in January, an insignificant increase in drought has been detected throughout the country, especially in the interior, in April. A significant increase in drought was determined in the summer months. One of the consequences of climate change is seasonal shifts. A further step in this study was the examination of seasonal shifts that occur after monthly changes. Although not statistically significant, especially in the spring months, there is a shift to the summer climate and sudden and heavy rainy periods in the summer. Sudden and severe precipitation can of course deceive drought calculation methods. It can be added that rainy seasons are shortened and dry seasons are prolonged.

Agriculture is the sector that most needs water. The cultivation areas, which show a sporadic nature in Turkey, occupy broad areas in certain places and vice versa. The summers are generally hot and dry in Turkey as water is a problem in agriculture. Turkey is a developed country in terms of agriculture and animal husbandry. The water demand is increasing daily due to its everincreasing population and growing cities. The best management of the existing water resources in the country is mandatory in all aspects in industrial, agricultural and social terms. Therefore, drought studies have become bestowed with much more scientific value. There are few drought analysis studies in the country with satellitesourced data. Thus, the findings of this study will broaden the current literature. For this reason, it is thought that this drought analysis study will shed light on the water resources projects planned for the future of the country and will contribute to the literature because of its method and periodic monthly based analysis. 


\section{REFERENCES}

Atalay I., 2011. Türkiye İklim Atlası, İnkılâp Kitabevi, İstanbul.

Aydeniz A., 1973. Tarımda verimliliğin sağlanmasında önemli etken olan su ve sulama durumumuz,Our water and irrigation status, which are important factors in ensuring productivity in agriculture Verimlilik Dergisi, 3/1: 177-199 [in Turkish].

CHRS Data Portal, Available at http://chrs.web.uci.edu/ SP_activities00.php [Accessed: 01.03.2021].

De Martonne E., 1942. Nouvelle carte mondiale de l'indice d'aridité. Annales de Géographie 51: 242-250.

Environmental Systems Research Institute (ESRI). 2012. ArcView GIS version 10.1, A computer software to visualize, explores, query and analyze data spatially, USA.

Erinç S., 1984. Klimatoloji ve Metotları, Climatology and Methods, İ.T.Ü. Deniz Bilimleri ve Coğrafya Enstitüsü, İstanbul, [in Turkish].

Gibbs J.W., Maher V.J., 1967. Rainfall Deciles as Drought Indicators, Bureau of Meteorology. Australia, 48, 33s.

Hsu K., Gao X., Sorooshian S., Gupta H.V., 1997. Precipitation estimation from remotely sensed information using artificial neural networks, Journal of Applied Meteorology, vol 36, no 9, 1176-1190.

Hsu K., Gupta H.V., Gao X., Sorooshian S., 1999. Estimation of physical variables from multiple channel remotely sensed imagery using a neural network: Application to rainfall estimation, Water Resources Research, 35(5), 1605-1618.

Hsu K., Gupta H.V., Gao X., Sorooshian S., 2000. Rainfall estimation from satellite imagery, chapter 11 of artificial neural networks in hydrology, edited by Govindaraju, R. S., Rao, A. R., published by Kluwer Academic Publishers, The Netherlands, pp 209-234.

Hsu K., Gupta H.V., Gao X., Sorooshian S., Imam B., 2002. SOLO-An artificial neural network suitable for hydrologic modelling and analysis, Water Resources Research, vol 38, no 12, 1302.

Keyantash A.J., Dracup A.J., 2004. An aggregate drought index: Assessing drought severity based on fluctuations in the hydrologic cycle and surface water storage, Water Resources Research, Vol 40, W09304. doi:10.1029/2003WR002610

Limones N., Pita-López M.F., Camarillo M.J., 2022. A new index to assess meteorological drought: the 1 Drought Exceedance Probability Index (DEPI)", Atmósfera, Vol 35 (1), enero (early online release). https://doi.org/10.20937/ATM.52870

Limones N., Marzo-Artigas J., Wijnen M., Serrat-Capdevilla A., 2020. Evaluating drought risk in data- scarce contexts. The case of southern Angola, Journal of Water and Climate Change, Vol 11, Issue S1. doi: 10.2166/wcc. 2020.101

Mallenahalli N.K., 2020. Comparison of parametric and nonparametric standardized precipitation index for detecting meteorological drought over the Indian region, Theoretical and Applied Climatology, 142:219236. https://doi.org/10.1007/s00704-020-03296-Z

McKee T.B., Doesken N.J., Kleist J., 1993. The Relationship of Drought Frequency and Duration to Time Scales, in Proceedings of the 8th Conference on Applied Climatology, 17.

Meteoroloji Genel Müdürlüğü (MGM). 2019. 2019 Climate Assessment, Ministry of Agriculture and Forestry, General Directorate of Meteorology, January 2020, Ankara.

Nalbantis I., 2008. Evaluation of a Hydrological Drought Index, European Water Publications, 23/24:67-77.

Nguyen P., Shearer E.J., Tran H., Ombadi M., Hayatbini N., Palacios T., Huynh P., Updegraff G., Hsu K., Kuligowski B., Logan W.S., Sorooshian S., 2019. The CHRS data portal, an easily accessible public repository for PERSIANN global satellite precipitation data, Nature Scientific Data, Vol 6, Article 180296.

Öztürk Z.M., Çetinkaya G., Aydın S., 2017. Climate Types of Turkey According to Köppen-Geiger Climate Classification, Journal of Geography, 35:17-27.

Palmer W.C., 1965. Meteorological Drought, U.S.weather Bureau, Research Paper No.45.

Pita M.F., 2000. Un nouvel indice de sécheresse pour les domains méditerranéens. Application au bassin du Gaudalquivir sudouest de l'Espagne, A new drought index for Mediterranean domains. Application to the Guadalquivir riverbasin in southwestern Spain, Publ. Assoc. Int. Climatol. 13, 225-234.

Salmi T., Maata A., Antilla P., Ruoho-Airola T., Amnell T., 2002. Detecting trends of annual values of atmospheric pollutants by the Mann-Kendall test and Sen's slope estimates - the Excel template application Makesens, Finnish Meteorological Institute, Helsinki, Finland, 35 pp.

Şen, Z., Almazroui M., 2021. Actual Precipitation Index (API) for Drought Classification, Earth Systems and Environment, 5:59-70. https://doi.org/10.1007/ s41748-021-00201-0

Sorooshian S., Gao X., Hsu K., Maddox R.A., Hong Y., Imam B., and Gupta H.V., 2002. Diurnal variability of tropical rainfall retrieved from combined GOES and TRMM Satellite Information, Journal of Climate vol 15, 983-1001.

Sorooshian S., Hsu K., Gao X., Gupta H.V., Imam B., Braithwaite D., 2000. Evaluation of PERSIANN sys- 
tem satellite-based estimates of tropical rainfall", Bulletin of the American Meteorology Society, vol 81, no 9, 2035-2046.

Sorooshian S., Nguyen P., Sellars S., Braithwaite D., Aghakouchak A., and Hsu K., 2014. Satellite-based remote sensing estimation of precipitation for early warning systems, Extreme Natural Hazards, Disaster Risks and Societal Implications, Cambridge University Press, 99-111.

Topçu E., Seçkin N., 2016. Drought Analysis of the Seyhan Basin by Using Standardized Precipitation Index (SPI) and L-Moments, Journal of Agricultural Sciences, 22:196-215. DOI: 10.1501/Tarimbil_0000001381

Tsakiris G., Vangelis H., 2005. Establishing a Drought Index Incorporating Evapotranpiration, European Water Publications, 9/10:3-11.

Vicente-Serrano SM., Santiago Beguería S., López-Moreno J., 2010. A multi-scalar drought index sensitive to global warming: the standardized precipitation evapotranspiration index - SPEI. J. Clim. 23, 1696-1718.

Weibull W., 1939. A statistical theory of strength of materials. Ing. Vetensk. Akad. Handl., 151: 1-45.

Wilhite D.A., Glantz M.H., 1985. Understanding: the drought phenomenon: the role of definitions, Water Int, 10(3):111-120. https://doi. org/10.1080/02508068508686328 